\title{
Teaching Technical Writing: Opportunities for International Collaboration
}

\author{
http://dx.doi.org/10.3991/ijep.v4i2.3438 \\ L. E. Seawright \\ Texas A\&M University at Qatar, Doha, Qatar
}

\begin{abstract}
Globalization of our modern economies requires a workforce that can move easily between time zones and cultures. Professors cannot ignore the drastic impact globalization has and will place upon engineering students. In order to be prepared for a competitive job market and the actual requirements of many engineering positions, students need to understand the constraints and challenges of working with colleagues that may live and work in different cultures, countries, languages, and contexts. However, engineering education rarely offers students an opportunity to practice the realities of our digital and intercultural working environments. This paper outlines one way to offer engineering students with collaborative, international, and intercultural writing projects. Students from a technical writing course in the United States were paired with engineering students in Qatar to develop a set of instructions using multimedia methods. Students learned a great deal from the real-world experience of writing and creating a project across two continents.
\end{abstract}

Index Terms-Intercultural communication, social media, teams, technical writing.

\section{INTRODUCTION}

For years engineering employers have lamented the sad state of recent-hires' communication and writing skills. In response, universities have rushed to provide new programs and special courses to prepare engineering students for the writing that is required in their field [1]. Several universities have recognized the need for specific english classes for engineering majors; however, few of the courses are actually taught by engineering professors. In most cases, the task of teaching these courses falls to english instructors but even more frequently, to adjunct faculty or graduate teaching assistants. These university faculty and staff are well equipped to teach the nuances of communication and grammar, but less prepared to teach engineering genres, discourses, ethics, or practices.

With all of these concerns, the role of international communication in engineering-specific english courses can easily be ignored by instructors unfamiliar and uncomfortable teaching students in such topics. However, today's workplace requires workers that adapt quickly to new colleagues and new organizational structures [2], an absolute necessity in a field like engineering where work is often performed internationally and collaboratively. Most instructors in engineering-specific english courses resort to relying on technical communication or other engineering-specific textbooks to address genres, ethics, and the international aspects of the field, but research suggests that these textbooks do a poor job in instructing students in the actual practices of Engineering in general [3] and international communication of Engineering in specific
[4]. How can non- engineering faculty and staff overcome these hurdles in order to better prepare neophytes for the field?

While pairing writing courses with specific engineering courses has been one way of bridging the instructor engineering- knowledge gap amongst english instructors and teaching assistants, this is only one aspect of preparing students for their future careers. Living and working in a globalized world where work happens over thousands of miles and multiple time-zones is a reality that our students will surely face. Preparing them for this reality by introducing assignments that require international teams to solve problems and create projects do not require discipline-specific knowledge on the part of the instructor, but they do provide students with the skills they will need as working engineers. This paper explores one way to set up such collaborative opportunities and the results of one such endeavor.

\section{PROJECT DESIGN}

In order to address the difficulties and complexities mentioned in the Introduction, a pilot project was designed to offer students a real- world international/intercultural experience. While this specific study required the cooperation of two instructors working at separate institutions teaching students that are physically present in the classroom, the project could also be modified for online students located in a variety of places and time zones.

\section{A. Preparing for the Course}

The pilot study consisted of two technical writing courses, one at public university in the United States and the other at an American university's branch campus located in Doha, Qatar. The actual selection of the two courses proved more complicated than one might assume. The Qatar campus, as a branch campus, would simply partner with a similar course at the main campus. However, in practice this proved to be difficult as instructors with busy schedules at both locations were unable to commit to the project. In addition, seemingly similar courses had different aims and student populations.

Another US university, unaffiliated with the Qatar campus, was identified as a potential study site due to its targeted english courses for engineers and its quality technical writing program. This site was able to provide a Graduate Teaching Assistant and an upper-level technical writing course to pair with the Qatar upper-level engineering technical writing course.

Although the two course instructors were not acquainted with each other prior to the pilot study, they were able to quickly develop rapport and determine various projects, assignments, and methodologies in order to pair the cours- 
es and give students an international team writing experience.

With the exception of one face-to-face meeting over the summer, all correspondence between the instructors was conducted using Facebook. This included sending proposed syllabi, articles, and lengthy messages to one another. The use of Facebook was a purposeful decision as it was assumed that students in the course could choose this social media site as a way to similarly correspond and collaborate. Of course the added benefit of a site like Facebook is that students (and instructors) can more easily get to know each other by reviewing personal profiles, pictures, and interests.

In order to provide a unified presentation of material and coordinate expectations, the same syllabus, textbook, readings, and project assignment descriptions were used in both classes. This allowed instructors and students the same course experience despite being on separate continents and time zones. The time of the project from initial lecture to completed presentations was four weeks.

\section{B. The Assignment}

Students from the two courses were assigned to international teams made of four to five students from each campus. The Qatar class had fewer students than the US class, so only two students from Qatar were assigned to each international team. The students were instructed to write a set of instructions for an audience of university students. The instructions needed to be purposeful and written for publication on a university or course website. Graphics and a multi-media presentation were required for the set of instructions. In addition, the teams were assigned specific software and presentation tools in order to create a set of instructions for the project. Topics assigned by instructors included GoAnimate, ReadCube, Excel graphs, Google Docs, Word picture tool, website design software, and survey software.

Students could select any method of multimedia presentation as long as it could be published on the internet. Recommended methods included Prezi, PowerPoint, YouTube video, PowToon, Google Drive, 280 Slides, and SlideRocket. The instructors recognized that some students would have to learn the assigned software and various presentation methods before completing the projects, but the effort in learning the software was a benefit to the team and to the students.

By learning new presentation software, students could more easily collaborate with their team members and build creative, effective demonstrations. Thus, the project allowed students more than the simple opportunity to create a set of instructions. They also acquired valuable software, project design, and problem solving skills.

\section{Student Collaboration}

A perfect pairing of students in number, major, and previous experience was impossible. The US university course was similar in structure and objectives but included both Engineering majors along with other pre-professional fields such as pre-med students. In addition, the US class was almost double the size of the Qatar class. The international teams reflected these differences with teams constructed of more US students than Qatari and a mix of Engineering and other majors.

Students were allowed to select their own modes and genres of communication including Skype, Google Docs, email, SMS messages, Facebook, etc. This was done in order to discover which modes students felt the most comfortable with initially and which modes would prove the most successful during the course of the project. Instructors required, however, that whatever mode of communication students selected all members of the team had to be included in each communication. For example, if students selected Facebook they would communicate with one another by building a Facebook group message or page so that all members could see and respond to all messages.

Prior to the start of the project, students were instructed on several facets of intercultural and collaborative communication. This is one area that similar studies had noted deficits [4]. Class discussions and lectures focused on cultural stereotypes, international experiences, intercultural experiences, and communication styles. Several articles were assigned for students in both courses that addressed these issues and gave them a background in intercultural studies and communication.

In order for students to be able to quickly know and feel comfortable with one another, students submitted personal profiles to their group members that included their name, interests, international experience, major, and likes/dislikes. After the initial dissemination of personal profiles, group members were required to turn in a group profile of all the members and detail how the group was organized and would communicate. Decisions on leadership, project task division, and presentation were left up to the group members.

\section{FINDINGS AND DISCUSSION}

Overall, students seemed pleased with the opportunity to experience working in an international team during their college coursework. Students, for the most part, enjoyed the experience and all noted that the experiment would be valuable for them in their future careers.

All of the group members in Qatar mentioned communication as their number one challenge and the contributing factor of problems that arose in the teams. It was found that teams who used alternatives to email, like social networking sites or Skype, fared far better than teams which used only email as the source of communication.

Similar to other studies recently published, students benefited collaboratively from the use of social media [5]. Members of teams who used Facebook recounted a better working atmosphere, feelings of trust amongst team members, and less frustration with time zone and distance. Teams who only used email, experienced a greater degree of frustration and a general unease with group members and the project as a whole. Even after teams were able to convince hold-out members to use Facebook after a challenging week or two of email-only communication, the resulting communications were not as successful as groups that started communication immediately using Facebook, Skype, and other methods along with email.

All students noted that face-to-face meeting would have been best and would have perhaps solved many of the group dynamics and communication problems. Of course, the ability to meet all team members on an Engineering project is not always a real-world possibility in actual work scenarios.

A surprising finding was that some students wanted much more oversight by the instructors. While several students noted it would have been helpful to require stu- 
dents to copy the instructors on all group emails, a couple of students went so far as wanting instructors to follow all group communication and take off points if teams members went beyond 24 hours of not responding. It is curious that some students saw the instructor as a being able (or willing!) to review hundreds of emails and keep up with a 24-hour response time.

This need to control the time in which students responded to one another seemed to be more of a concern to the Qatari students than the US students. Qatari students also claimed that they worked harder than the US students, despite being complimentary about one or two Americans in each team.

It could be that the communication issue was not as much "a problem" as it was a "learning curve" for students working in an international project for the first time. They admit that while communication was a major factor at the beginning of the project, by the last week, no one in either country was complaining about lack of response from any team member.

A few of the students in Qatar also complained that they felt the students in the US did not really want to get to know them. Both instructors made an effort to assign personal and group profiles in order to help the students get to know one another at the beginning of the project, and while many took the profiles seriously and began excellent communication on a personal level, other students felt that the US students either didn't care about getting to know them or were too busy to commit to using Facebook or other social media that would have enabled better socialization.

In future collaborative projects, it would be beneficial to organize the project in much the same way but require that groups decide on a way to communicate besides simple email. It is clear that groups which used Facebook and Skype had better experiences and collaborations. In addition, deliverables should be assigned for the groups to complete every few days with one large project at the end so that students can cooperate with each other on projects and have more communication in the weeks leading up to the larger assignment. The quality of work the students produced was quite good. The level of professionalism and maturity displayed in their final multimedia presentations was excellent.

While this collaborative project was only four weeks in duration, students would benefit from a course that was paired for an entire semester. This would allow teams to work on a series of small projects that could culminate in a larger presentation or document that could be viewed by all the class members on each continent.

\section{CONCLUSIONS}

Students were very interested in the project and the idea of communicating with students a continent away. None of the students had previously worked collaboratively with students in another country, and the experience seemed a valuable one.

Instructors who may want to conduct a project such as this need careful organization and planning with the other course instructor. Syllabi for the selected period of time should be identical so students in both courses are learning the same material and receiving the same lectures during the project time period. Instructors also need to be flexible and prepared to change assignment details or ancillary projects if needed. Instructors should not let the complexity of organization required for such projects discourage them from creating similar international collaborative experiences for their own students, however, because it is obvious that students enjoyed and derived benefits from the activity.

While this pilot study was conducted at unaffiliated schools, future collaborative efforts would benefit by pairing a course at a branch campus with a course at the main campus. This would afford instructors a better chance of knowing one another and understanding the university culture and students. In addition, this kind of pairing would allow for better communication between instructors and students and allow students to select a set of instructions that is relevant to the university system.

In addition, students should not be graded solely on the final project. Working collaboratively across continents is complicated, so students should, in addition to the final project, also be graded on their individual reflections of the activity, personal profile, group member updates, and peer reviews. It is also possible to have each student in the group assigned a particular part of the project so that individuals can be graded on their specific efforts as well.

Overall, this project provides students with valuable skills that they will need in the future as working engineers. The ability to communicate with other people located in various countries is a skill most students have little chance to practice during college courses. Providing students with experiences similar to this one enriches their education and better prepares them for the world they will live and work in as engineers.

\section{ACKNOWLEDGMENT}

Seawright thanks Afrin Zeenat, the US collaborating instructor, for her commitment to the project.

\section{REFERENCES}

[1] L. Reave, "Technical communication instruction in engineering schools: a survey of top-ranked U.S. and Canadian programs," in Journal of Business and Technical Communication, vol. 18, pp. 452-490, 2004.. http://dx.doi.org/10.1177/1050651904267068

[2] J. Wolfe, "How technical communication textbooks fail engineering students," in Technical Communication Quarterly, vol. 18(4), pp. 351-375, 2009. http://dx.doi.org/10.1080/10572250903149662

[3] E.A. Thrush, "Bridging the gaps: technical communication in an international and multicultural society," in Technical Communication Quarterly, Vol. 2(3), pp. 271-283, 1993. http://dx.doi.org/10.1080/10572259309364541

[4] M.C. Paretti, L.D. McNair, and L. Holloway-Attaway, "Teaching technical communication in an era of distributed work: a case study of collaboration between US and Swedish students," in Technical Communication Quarterly, vol. 16(3), pp. 327-352, 2007. http://dx.doi.org/10.1080/10572250701291087

[5] R. Faizi, A. El Afia and R. Chiheb, "Exploring the potential benefits of using social media in education," in iJEP Journal, vol 3(4), pp. 50-53, 2013.

\section{AUTHOR}

L.E. Seawright is with Texas A\&M University at Qatar in Doha, Qatar (leslie.seawright@qatar.tamu.edu). She is an Assistant Professor of English.

This article is an extended and modified version of a paper presented at the 16th International Conference on Interactive Collaborative Learning (ICL2013) and 42nd IGIP International Conference on Engineering Pedagogy, held from 25 to 27 September 2013 at Kazan National Research Technological University, in Kazan, Russia. Submitted 30 November 2013. Published as re-submitted by the author 17 March 2014. 